\title{
Energy and economic performance of the FARWIND energy system for sustainable fuel production from the far-offshore wind energy resource
}

\author{
Aurélien Babarit, Edwin Body, Jean-Christophe Gilloteaux, Jean-François Hétet \\ LHEEA \\ Centrale Nantes - CNRS \\ 1, rue de la Noë, 44300 Nantes, France \\ Email: aurelien.babarit@ec-nantes.fr
}

\begin{abstract}
Since 2016, Ecole Centrale de Nantes has been investigating a radically new technology for conversion of the far-offshore wind energy into sustainable fuel, called the FARWIND energy system. It relies on mobile wind energy converters (energy ships) that are not gridconnected. Thus, the converters include on-board powerto-X plants for storage of the produced energy. In [16], we investigated the feasibility of hydrogen as the energy vector. It was found to be challenging because of high transportation and distribution cost due to the low volumetric energy density of hydrogen for standard conditions of temperature and pressure. In this paper, we first investigate other options which include synthetic natural gas, methanol, Fischer-Tropsch fuel and ammonia. Comparison of those options indicates that methanol is the most promising option. Then, net energy efficiency and cost of FARWIND-produced methanol is estimated. Despite the fact that the net energy efficiency is found to be smaller than for the hydrogen solution, it is shown that the methanol cost could be competitive for the transportation fuel market on the medium to long term.
\end{abstract}

Keywords-offshore wind energy, energy ship, powerto-liquid, methanol, sustainable fuel, energy efficiency, cost of energy

\section{INTRODUCTION}

The share of fuels is still expected to be around 50\% of the total EU final energy consumption in 2050 [1]. Therefore, to achieve a global temperature change of less than $2{ }^{\circ} \mathrm{C}$ as set out in the Paris agreement, there is a critical need to develop low-carbon alternatives (sustainable fuels) to fossil fuels.

A promising option is the production of sustainable fuel from renewable energy sources through Power-toGas and Power-to-Liquid processes (PtX processes) [2]. Prototypes have been developed, e.g. Jupiter 1000 in France [3], Rozenburg PtG plant in the Netherlands, Audi e-gas in Germany [2], SOLETAIR in Finland [4], George
Olah PtL plant in Iceland [5], etc. However, the main challenge faced by PtX products from renewable energybased plants is cost competitiveness. Key economic drivers are the input cost of electricity to the PtX plant and the capacity factor of the PtX plant [6]. Unfortunately, there is currently no commercial renewable power generation technology can combine large-scale deployment potential, low cost of generated electricity and high capacity factor which is required for the large-scale synthesis of competitive sustainable fuel from PtX processes.

To address this challenge, Centrale Nantes has been developing since 2016 a new concept for the production of sustainable fuel from the yet-untapped far-offshore wind energy resource. It is called the FARWIND energy system (Fig. 1). It includes two essential subsystems. The first one is a fleet of mobile autonomously-sailing energy ships (FARWINDERs) producing sustainable fuel from wind energy. Energy ships are ships propelled by sails that produce electricity using water turbines attached underneath their hull [7]. Since they are not gridconnected, the produced electricity must be stored onboard. The use of batteries has been proposed by Platzer \& Sarigul-Klijn [7]. However, high gravimetric and volumetric energy density are key requirements for high performance FARWINDERs (low energy density leads to heavy and slow ships which are less efficient than light and fast ships) [8][9]. In this respect, the conversion of the produced electricity into fuel through $\mathrm{PtX}$ processes is the most promising solution [10]. Thus, FARWINDERs include on-board Power-to-X (PtX) plants.

The second subsystem is a specific tanker which supplies the FARWINDERs with the necessary feedstock for the PtX plant to operate, and collects the produced fuel. The tanker also acts as a surveillance, control and service vessel to ensure continuous and safe (e.g. failure 


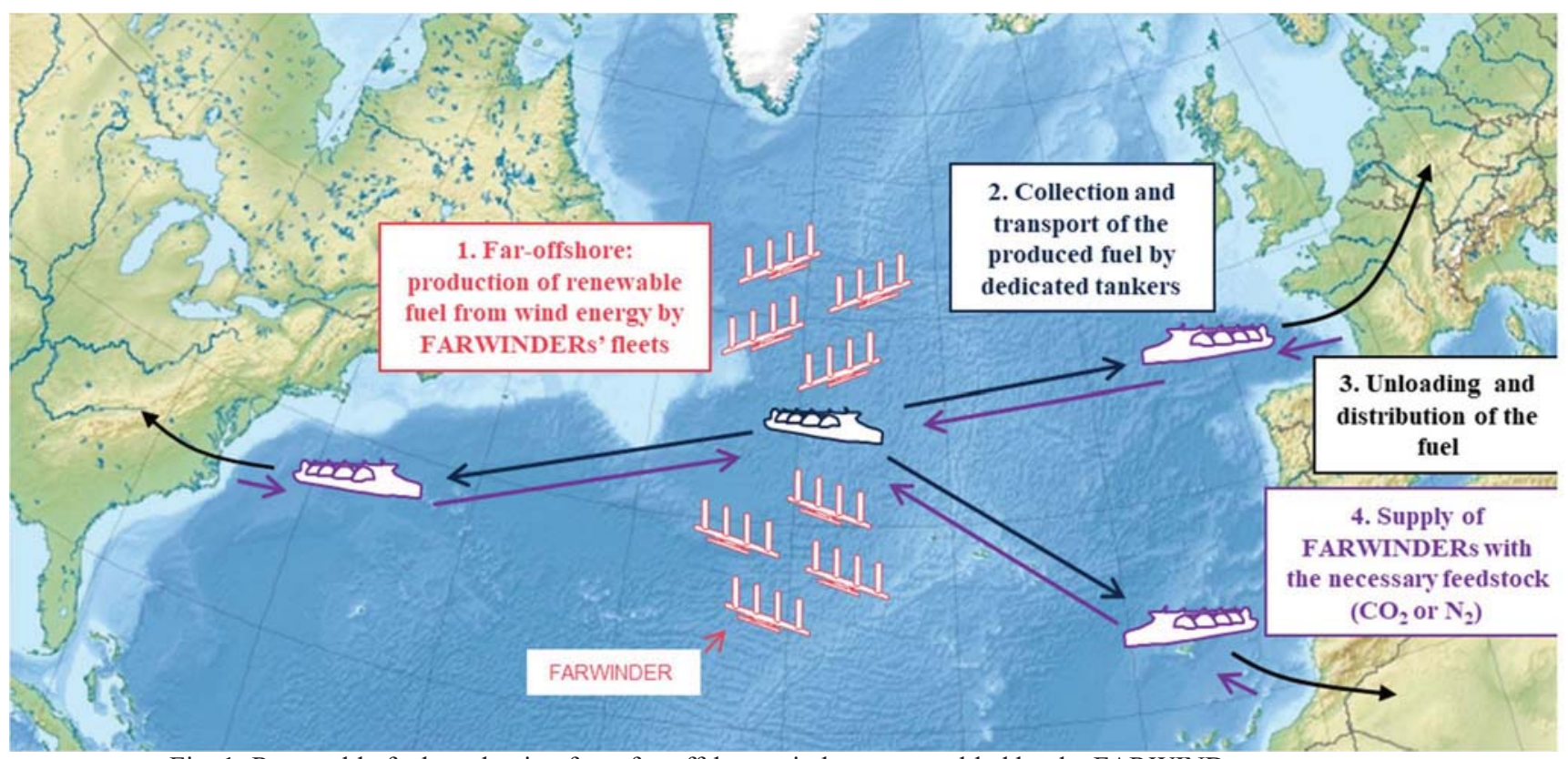

Fig. 1: Renewable fuel production from far-offshore wind energy enabled by the FARWIND energy system

or a FARWINDER) and secure (e.g. piracy) energy production.

There are several conceptually feasible options for the energy vector: hydrogen, synthetic hydrocarbons (synthetic natural gas, methanol, Fischer-Tropsch synthetic fuel) and ammonia. Hydrogen may appear as the obvious choice for energy storage aboard FARWINDERs. Indeed, the process through which electricity is converted into hydrogen (water electrolysis) is well known. Moreover, there are electrolyzer technologies that are fully mature [2], including commercially available containerized electrolysers [11] which may be simple to integrate aboard a vessel such as a FARWINDER. Therefore, it is not surprising that hydrogen has been selected as the energy storage solution in most energy ships proposals [8][12][13][14][15].

However, the low volumetric energy density for standard conditions of temperature and pressure is a wellknown challenge for hydrogen storage and transportation. In [16], we investigated the energy efficiency and cost of storage and transportation of hydrogen produced in the far-offshore to land-based consumers. We found that energy losses directly related to storage and transportation would be in the order of $50 \%$ of the transported energy, and that storage and transportation cost would account for nearly half of the cost of the fuel.

In contrast, the other possible energy vector options (synthetic natural gas (SNG), methanol (MeOH), FischerTropsch fuel (FT fuel), ammonia $\left(\mathrm{NH}_{3}\right)$ ) can be expected to be significantly simpler to store and transport, which could result in significantly smaller cost for those stages. Moreover, in contrast to hydrogen, those products can be used into existing infrastructures with limited to no modifications.
The processes for electrochemical production of synthetic hydrocarbons (SNG, $\mathrm{MeOH}$ and FT fuel) first involve the production of hydrogen (through water electrolysis) and second the combination of the produced hydrogen with carbon dioxide $\left(\mathrm{CO}_{2}\right)$. As for the production of ammonia, the hydrogen is combined with nitrogen $\left(\mathrm{N}_{2}\right)$. The additional step in the energy conversion process (compared to hydrogen) is a drawback since it leads to an additional energy loss, which reduces the overall energy efficiency. Moreover, this additional conversion step increases the size and complexity of the power-to-X plant, which might render challenging its integration and autonomous operation aboard a FARWINDER. Finally, these processes require the supply of a feedstock (carbon dioxide or nitrogen) to the power-to-X plant in addition to electricity.

Nevertheless, all those drawbacks may be more than compensated by the easier storage and transportation of the products, and also the fact that they can be easily used in existing infrastructures. The aim of this study is to investigate this question.

The rest of this paper is organized as follows: in section II, we present a possible FARWINDER design and the expected cost of electricity available onboard. In section III, we compare the possible options for the power-to-X plant. In section IV, we estimate the energy loss for the transportation of the most promising fuel option (methanol) from the far-offshore to end users located inland. The energy cost of $\mathrm{CO} 2$ production is taken into account. In section V, the cost of FARWINDproduced methanol is estimated. Section VI is the conclusion of the paper. 


\section{FARWINDER DESIGN AND COST OF ELECTRICITY}

Using a velocity and power prediction program developed in previous work [8], we developed a preliminary design for the FARWINDER, Fig. 2. It is a $80 \mathrm{~m}$ long catamaran fitted with three $30 \mathrm{~m}$ Flettner rotors, acting as sails. The catamaran hull shape is inspired by the $86 \mathrm{~m}$ long $26 \mathrm{~m}$ wide HMAS Jervis Bay wave piercing catamaran [17]. Flettner rotors are rotating vertical cylinders with their axis perpendicular to the wind. Thanks to the Magnus effect, the action of the wind on the cylinder generates a lift force which is perpendicular to both the wind direction and the axis of the cylinder. $30 \mathrm{~m}$ tall Flettner rotors are commercially available from the company Norsepower [18]. The diameter of the rotor of the water turbine is $6 \mathrm{~m}$.

We estimated that this design can generate $1 \mathrm{MW}$ of electric power for a true wind speed of $10 \mathrm{~m} / \mathrm{s}$ [19]. Regarding the on-board electricity cost, it is challenging to estimate as no energy ships have been built yet. Nevertheless, using as a starting point the expected levelised cost of energy for commercial floating wind turbines, it was estimated in [16] that a long term cost of $0.04 € / \mathrm{kWh}$ could be achieved. For the short term, a cost of $0.08 € / \mathrm{kWh}$ was suggested, which we will consider in this study.

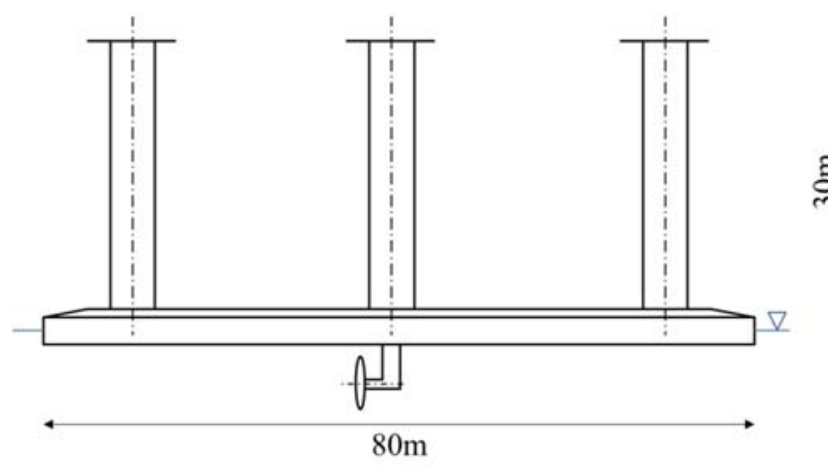

Fig. 2: Schematic of the FARWINDER design

III. COMPARISON OF POSSIBLE OPTIONS FOR THE POWER-TO-X PLANT

Each FARWINDER includes a power-to-X plant for energy storage. The conceptually feasible options for the energy vector are synthetic hydrocarbons and ammonia. They are reviewed and compared in this section.

\section{A. Power-to-hydrocarbon plant}

The first step in a power-to-hydrocarbon plant is the conversion of electricity into hydrogen using water electrolysis:

$$
\mathrm{H}_{2} \mathrm{O} \rightarrow \mathrm{H}_{2}+\frac{1}{2} \mathrm{O}_{2}
$$

The second step is the combination of the produced hydrogen with carbon dioxide. Depending on the process, the resulting product can be synthetic natural gas, methanol or Fischer-Tropsch fuel. It can be noted that the TRL (technology readiness level) of those PtX technologies is in the range of 5 to 8 for stationary landbased applications [2][20]. Examples of PtX demonstration plants include the $6 \mathrm{MW}$ power-to-SNG Audi e-gas plant [2][21], the $1 \mathrm{MW}$ power-to-SNG Jupiter 1000 plant [3], the 4,000 tonne/a power-tomethanol Georges Olah plant [5], and the $5 \mathrm{~kW}$ powerto-FT fuel SOLETAIR plant [4].

Synthetic natural gas is obtained through catalytic methanation [2]. The reaction (Sabatier's reaction) is:

$$
\mathrm{CO}_{2}+4 \mathrm{H}_{2} \rightarrow \mathrm{CH}_{4}+2 \mathrm{H}_{2} \mathrm{O}
$$

For direct methanol synthesis $\left(\mathrm{CO}_{2}\right.$ hydrogenation), the reaction is [22]:

$$
\mathrm{CO}_{2}+3 \mathrm{H}_{2} \rightarrow \mathrm{CH}_{3} \mathrm{OH}+\mathrm{H}_{2} \mathrm{O}
$$

Methanol can also be obtained indirectly through the two steps CAMERE process, which involves first the partial conversion of carbon dioxide into carbon monoxide via the reverser water-gas shift reaction, and then the conversion of the mixture into methanol. However, according to [5] and [22], the direct methanol synthesis is more efficient from the energy perspective. According to [5], the cost of produced methanol is comparable in the two processes. It can be noted that Kim \& Park were the first to suggest the use of methanol for energy storage aboard energy ships [14].

For the FT fuel, the reaction (Fischer-Tropsch synthesis) is [6]:

$$
n \mathrm{CO}_{2}+3 \mathrm{nH}_{2} \rightarrow\left(-\mathrm{CH}_{2}-\right)_{n}+2 \mathrm{nH}_{2} \mathrm{O}
$$

Note that the FT fuel contains different chains of synthetic hydrocarbons including naphta, jet-fuel, diesel, lubes, wax, ... Thus, the FT fuel can be considererd as the synthetic equivalent of crude oil. In [23], Platzer \& Sarigul-Klijn were the first to suggest the conversion of electricity produced by energy ships in FT fuel, in order to provide carbon-neutral jet fuel for decarbonisation of the aviation sector.

According to [2], the energy efficiency of the powerto-SNG process is in the order of $55 \%$ in practice $(54 \%$ efficiency has been reported for the Audi e-gas plant [21]). For methanol, the electric power needed to produce $28,757 \mathrm{t}_{\mathrm{MeOH}} / \mathrm{h}$ with the direct methanol synthesis process is $310 \mathrm{MW}$ according to [22]. The lower heating value of 
methanol being $5.5 \mathrm{kWh} / \mathrm{kg}$, the energy efficiency is $51 \%$. According to [24], it takes 0.193 tonnes (6.45 $\mathrm{MWh}_{\mathrm{th}}$ ) of hydrogen and $0.45 \mathrm{MWh}$ of electricity to produce 5.58 MWh (1.015 tonne) of methanol. The process efficiency is thus $81 \%$ for the conversion of hydrogen and $\mathrm{CO}_{2}$ into methanol. According to [2], alkaline electrolyzers' efficiency is typically $60 \%$. It leads to a power-to-methanol efficiency of $49 \%$, close to the $51 \%$ of [22]. In [25], the direct and the indirect methanol synthesis processes were modelled. It is reported that 99,040 tonnes of hydrogen and 0.94 $\mathrm{kWh} / \mathrm{t}_{\mathrm{MeOH}}$ of electricity are required to produce 464,000 tonnes. Assuming an electrolyzer efficiency of $60 \%$, it corresponds to power-to-methanol efficiency of $43 \%$, which is lower than the two other studies. It may be explained by the significanlty greater hydrogen consumption per $\mathrm{kg}$ of methanol $(10 \%)$ than in the other studies. In the present study, we will assume the powerto-methanol efficiency to be $49 \%$ henceforth. For FT fuel, the process efficiency is approximately $39 \%$ according to [23]. Thus, it appears that the power-to-SNG process is $41 \%$ more efficient than the power-to-FT fuel process and $12 \%$ more efficient that the power-tomethanol process. Note that the process efficiencies do not take into account the energy required for fresh water supply to the electrolyzer nor the energy required for $\mathrm{CO}_{2}$ production and supply. For energy ships, fresh water can be obtained through seawater desalination. Its power requirement is negligible in comparison to the power consumed by the electrolyzer [6].

Conceptually, $\mathrm{CO}_{2}$ could be produced aboard the FARWINDERs, for example using direct air capture technologies [26]. However, this would increase the size and complexity of the power-to-X plant, which is undesireable. Therefore, we consider that the $\mathrm{CO}_{2}$ is produced on-shore and transported to the FARWINDERs by the tankers. The corresponding energy requirements are discussed in the next section.

From an energy efficiency perspective, SNG production appears to be the most favourable option. Let us now consider the market perspective. The market volume is considerable for all three options (in the order of 4,000 Mt/y for FT fuel (oil market), 2,000 Mt/y for natural gas and $80 \mathrm{Mt} / \mathrm{y}$ for methanol). However, the market value of methanol and FT fuel is in the order of $60 € / \mathrm{MWH}_{\text {th }}$ whereas it is in the order of $20 € / \mathrm{MWH}_{\text {th }}$ for natural gas. Moreover, in contrast to natural gas, methanol and FT fuel are liquid for standard conditions of temperature and pressure, which is a key advantage with respect to transportation and distribution.

\section{B. Power-to-ammonia plant}

As for the power-to-hydrocarbon plant, the first step also consists in production of hydrogen (1). Then, ammonia is obtained through the Haber-Bosch process:

$$
\mathrm{N}_{2}+3 \mathrm{H}_{2} \rightarrow 2 \mathrm{NH}_{3}
$$

Nowadays, over 170 million tonnes of ammonia are produced annually for industrial purposes using this process [27]. The market value is in the range 20-40 $€ / \mathrm{MW}_{\text {th }}$ depending on the natural gas cost (which is usually used to produce hydrogen through the steam methane reforming process).

Most ammonia plants have orders of magnitudes of capacity greater than that required for a FARWINDER (100MW-scale). However, small-scale power-toammonia plants (MW-scale) are currently in development [28], but haven't been demonstrated yet. Thus, the TRL of small-scale power-to-ammonia plant is arguably 4-5. Their energy efficiency is expected to be in the order of $47 \%$ [28].

In contrast to the power-to-hydrocarbon plants, this efficiency takes into account the energy required to produce the nitrogen necessary to the process. It is extracted from air using an air separation unit. According to [29], the energy requirement is negligible in comparison to the energy consumed by the electrolyzer (less than $1 \%$ ).

Nitrogen could be produced aboard the FARWINDERs. However, in order to reduce the complexity of the FARWINDERs (as for the case of hydrocarbon fuels), it is considered that nitrogen would be produced on-shore and transported to the FARWINDERs by the tankers.

\section{Discussion}

TABLE I. COMPARISON OF ENERGY EFFICIENCY AND MARKET VALUE FOR THE FUELPRODUCTION OPTIONS FOR FARWINDERS

\begin{tabular}{|c|c|c|c|c|}
\hline Product & Process & $\begin{array}{c}\text { State for } \\
\text { STP }\end{array}$ & $\begin{array}{c}\text { Energy } \\
\text { efficiency }\end{array}$ & $\begin{array}{c}\text { Market } \\
\text { value } \\
\left(\boldsymbol{€} / \mathbf{M W h}_{\text {th }}\right)\end{array}$ \\
\hline $\begin{array}{c}\text { Synthetic } \\
\text { natural gas }\end{array}$ & $\begin{array}{c}\text { Catalytic } \\
\text { methanation }\end{array}$ & Gas & $55 \%$ & 20 \\
\hline Methanol & $\begin{array}{c}\text { Methanol } \\
\text { synthesis }\end{array}$ & Liquid & $49 \%$ & 60 \\
\hline FT fuel & $\begin{array}{c}\text { Fischer- } \\
\text { Tropsch } \\
\text { synthesis }\end{array}$ & Liquid & $39 \%$ & 60 \\
\hline Ammonia & $\begin{array}{c}\text { Haber- } \\
\text { Bosch } \\
\text { process }\end{array}$ & Gas & $47 \%$ & $20-40$ \\
\hline
\end{tabular}




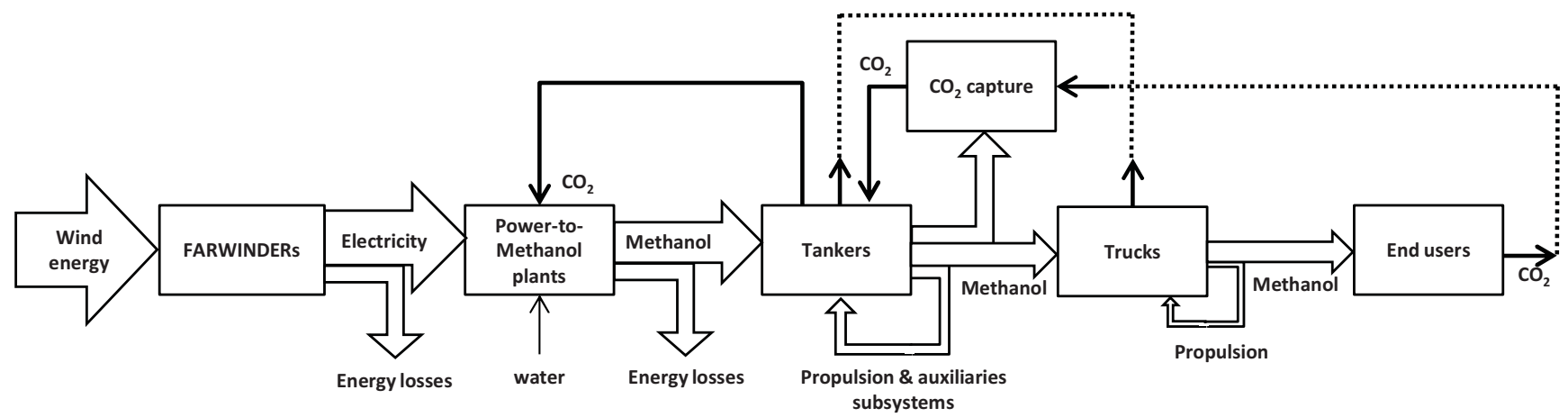

Fig. 3: Simplified flow diagram for the energy and products in a methanol-producing FARWIND energy system

Tab. 1 shows the comparison of the energy efficiency and market value for the fuel production options for FARWINDERs. One can see that the most promising option is methanol as it is liquid for standard conditions of temperature and pression (STP), it has good energy efficiency and it has the greatest market value. Therefore, methanol was selected for the final energy product for the FARWIND energy systems.

\section{ESTIMATE OF THE NET ENERGY EFFICIENCY}

\section{A. Estimate of the energy cost of methanol and $\mathrm{CO}_{2}$ transportation}

In [30], we optimized the energy production of fleets of FARWINDERs deployed in the North Atlantic ocean using weather-routing. Three years were considered: 2015, 2016 and 2017. It was assumed that the arrival point and the starting point of the FARWINDERs routes are one and the same, whose coordinates are: N 54.51660; W 27.551844 (mid-distance between Ireland and Newfoundland, Canada). Results show that capacity factors over $80 \%$ can be achieved. In contrast, smaller capacity factors were obtained when the starting/arrival point of the FARWINDERs was set to a European port (Saint-Nazaire, France). It indicates that it is beneficial for energy production that the FARWINDERs remain deployed in the far-offshore. The drawback is that tankers are required to supply $\mathrm{CO}_{2}$ to the FARWINDERs and collect the produced methanol. The energy required to operate the tankers must be taken into account in the energy balance.

The energy requirement depends on the characteristic of the tankers. Let us estimate the masses of carbon dioxide and methanol that need to be transported. In [30], it was found that the average route duration is 6 days. Therefore, we will consider 7 days at full capacity for the design of the storage tanks of the FARWINDERs. The rated power production of the FARWINDER being 1 MW and the energy efficiency of the power-to-methanol plant being $49 \%$, the methanol tank capacity is approximately 15 tonnes. As it takes $1.375 \mathrm{~kg}$ of carbon dioxide to produce $1 \mathrm{~kg}$ of methanol, the carbon dioxide tank capacity is approximately 20 tonnes.

Let us now estimate the number of FARWINDERs that can be serviced by one tanker. It depends on the duration of the $\mathrm{CO}_{2}$ loading and methanol unloading operation. We assume that this operation takes 6 hours in average and that they are carried out continuously (including during the night). Therefore, one tanker can service 28 FARWINDERs per week. It corresponds to the supply of 560 tonnes of carbon dioxide and the collection of 420 tonnes of methanol every week.

The tankers are assumed to be operated by a crew. The duration of their mission is supposed to be 4 weeks. At the end of its 4 weeks mission, the tanker goes back to a shore-based terminal to change crew, unload the methanol and load $\mathrm{CO}_{2}$. Therefore, their total $\mathrm{CO}_{2}$ capacity must be 2,240 tonnes and the total methanol capacity must be 1,680 tonnes. The $\mathrm{CO}_{2}$ is supposed to be liquid, thus it requires a cryogenic storage tank. According to [31], the empty weight of a 41.5 tonnes capacity liquid $\mathrm{CO} 2$ storage vessel is 26 tonnes. For methanol, the empty weight of a tank of 15,000 gallons capacity (45 tonnes) is 9 tonnes [32]. Therefore, it can be estimated that the total empty weight of the tanks is approximately 1,800 tonnes $\left(1,400\right.$ tonnes for the $\mathrm{CO}_{2}$ tank and 400 tonnes for the methanol tank). The configuration with the maximum cargo weight $(4,040$ tonnes) is when the tanker leaves the terminal (full $\mathrm{CO}_{2}$ tank and empty methanol tank).

As in [16], it is assumed that the FARWINDERs are deployed at a distance of $1,000 \mathrm{kms}$ from shore. Therefore, the tankers have to travel $1,000 \mathrm{kms}$ to meet the FARWINDERs, and 1,000 kms more when going back to the terminal. Let us estimate the energy consumption for those travels. According to [33], the propulsion power of a 5,000 tonnes deadweight bulk carrier is $1,410 \mathrm{~kW}$ for a service speed of 12 knots. At this speed, it will take 45 hours for the tanker to reach the FARWINDERs' deployment area. Assuming an engine efficiency of $40 \%$, the energy consumption is then 159 
$\mathrm{MWh}_{\mathrm{th}}$. Once arrived in the deployment area, it is assumed that the tanker remains stationary. The power consumption is thus reduced to what is necessary to power the auxiliaries subsystems. It is assumed that it corresponds to $20 \%$ of the propulsion power, i.e. 282 $\mathrm{kW}$. It leads to an energy consumption of $190 \mathrm{MWh}_{\text {th }}$ over the 4 weeks of the tanker's mission. Finally, an additional $159 \mathrm{MWh}_{\text {th }}$ is consumed at the end of the mission for the return trip to the terminal.

The total energy consumption for the methanol and $\mathrm{CO}_{2}$ transportation is thus $508 \mathrm{MWh}_{\text {th }}$, which corresponds to 92 tonnes of methanol, i.e. $5.5 \%$ of the total transported production. It can be noted that this figure is half that of the energy required to mine, transport and refine fossil fuels according to [34]. Nevertheless, it should also be noted that it is highly uncertain as it strongly depends on the numerous assumptions that were made (FARWINDERs tank capacity, duration of loading and unloading operation, duration of mission).

\section{B. Energy cost of $\mathrm{CO}_{2}$ production}

The ambition of the FARWIND energy system is to provide a sustainable alternative to the use of fossil fuels. Therefore, we shall consider that the final uses for the produced methanol will be the same as for fossil fuels, i.e transportation and heat and power generation. In those uses, the chemical energy is released through combustion, which results in $\mathrm{CO}_{2}$ emissions of 0.25 $\mathrm{kg} / \mathrm{kWh}$ th. For the produced methanol to to be truly sustainable, the carbon cycle must be circular. Therefore, the source of $\mathrm{CO}_{2}$ supply in the FARWIND energy systems must be the atmosphere, either directly or indirectly.

Several Direct Air Capture (DAC) technologies are currently in development [26][35]. They include dry absorption, wet absorption and membrane filtration. As can be inferred by the name of the technology, DAC allow separating and collecting $\mathrm{CO} 2$ directly from ambient air. The energy requirement is expected to be in the range [1.8-2.45] $\mathrm{kWh} / \mathrm{kg}_{\mathrm{CO} 2}$ depending on the process, which is significant. However, note that more than $80 \%$ of the required energy is low grade heat $\left(100-110^{\circ} \mathrm{C}\right)$ [6][35]. Therefore, there may be uses (e.g. power generation) for which waste heat can be recovered in order to capture the $\mathrm{CO}_{2}$ emissions with limited to none additional power consumption (and thus limited to no impact on the overall energy efficiency).

Indirect air capture technologies include carbon capture from biomass combusion and $\mathrm{CO}_{2}$ extraction from seawater. For carbon capture from biomass combustion, carbon dioxide in the atmosphere is firstly captured by plants. The biomass (e.g. wood) is then collected and the energy is used through combustion (e.g. in a biomass power generation plant or a cement plant). The $\mathrm{CO}_{2}$ in the flue gases, which is hundreds times more concentrated than in ambient air, can then be captured more effectively than with DAC. Assuming that the energy cost of carbon capture from of biomass plant is similar to that for a coal-fired plant, it is in the order of $0.6 \mathrm{kWh} / \mathrm{kg}_{\mathrm{CO} 2}$ according to [36]. Carbon dioxide may also be extracted from seawater [37]. Indeed, some of the $\mathrm{CO} 2$ present in the atmosphere dissolves in the ocean (which is why the raising concentration of $\mathrm{CO}_{2}$ in the atmosphere leads to the current acidification of the oceans). However, this new technology is in its early stages of development and the energy requirement is unclear [38].

In any case, the captured $\mathrm{CO}_{2}$ must be liquefied for efficient transportation. The energy requirement for $\mathrm{CO}_{2}$ liquefaction is in the order of $0.1 \mathrm{kWh} / \mathrm{kg}_{\mathrm{CO} 2}$ according to [39], which is low.

Finally, the range [0.7-2.6] $\mathrm{kWh} / \mathrm{kg}_{\mathrm{CO} 2}$ is retained for the energy cost of $\mathrm{CO}_{2}$ production and liquefaction, with the low end of the range corresponding to liquid $\mathrm{CO}_{2}$ captured from the flue gas of a biomass-fired power plant, and the high end of the range corresponding to a pessimistic estimate for DAC.

\section{Net energy efficiency}

Fig. 3 summarizes the energy and products flow in a methanol-producing FARWIND energy system. Let us evaluate the net energy efficiency from the input electricity to the power-to-methanol plant to the end users of the produced energy.

The efficiency of the power-to-methanol plant is $49 \%$. Recalling that the lower heating value of methanol is $5.5 \mathrm{kWh} / \mathrm{kg}$, the energy required to produce $1 \mathrm{~kg}$ of methanol is $11.2 \mathrm{kWh}$. The rated power of the FARWINDERS being $1 \mathrm{MW}$ and assuming a capacity factor of $80 \%$, the annual methanol production is 625 tonnes.

It has been assumed that each tanker provides $\mathrm{CO}_{2}$ and collects the produced methanol of 28 FARWINDERs, that its mission duration is 4 weeks and that the round trip to the terminal for methanol unloading and $\mathrm{CO}_{2}$ loading takes 90 hours, i.e 3.75 days. The duration of that period of time during which the tanker is away from the FARWINDERs is increased to one week to take into account the duration of unloading/loading operations and other maintenance operations. To ensure continuous operation of the FARWINDERs, tankers must be replaced immediately when they leave the production zone Therefore, each group of 28 FARWINDERs must be supported by more than 1 tanker. It can be shown that the minimum number of tankers per fleet must be at least 1.25. It means that the optimal fleet size comprises 112 
FARWINDERs supported by 5 tankers. Over a year, the number of round-trips between the terminal and the production zone is 10.4 for each tanker. Therefore, the total energy consumption for the operation of the 5 tankers is $21.1 \mathrm{GWh}$ per annum and the amount of methanol loaded by the tankers is 70,000 tonnes per annum. Assuming that the tankers run on methanol, their consumption is 3,830 tonnes per annum. The remainder is then 66,170 tonnes. The energy required per $\mathrm{kg}$ of methanol delivered at the unloading terminal is thus increased to $11.8 \mathrm{k} \mathrm{Wh} / \mathrm{kg}$.

Once the methanol is arrived at the terminal, it still needs to be distributed to end-users, which can be achieved using trucks. $45 \mathrm{~m}^{3}$ (35.6 tonnes) methanol tank trailers are commercially available [40]. Following [16], it is assumed that the farthest end-user is $600 \mathrm{~km}$ from the methanol terminal. Thus, the round-trip to deliver methanol to such end-users by truck would take 2 days assuming an average truck speed of $60 \mathrm{~km} / \mathrm{h}$. The typical fuel consumption of semi-trailer trucks is $40 \mathrm{~L}$ of diesel per $100 \mathrm{~km}$, corresponding to approximately 4.8 $\mathrm{kWh} / \mathrm{km}$. Therefore, the energy consumption for a 1,200 $\mathrm{km}$ round-trip would be $5,760 \mathrm{kWh}$. Assuming that the truck runs on methanol, its consumption would be 1.05 tonnes, i.e. $3 \%$ of the transported methanol. The remaining fuel available for the end user would then be 34.5 tonnes. The energy required per $\mathrm{kg}$ of methanol delivered to the end user would increase to $12.2 \mathrm{kWh} / \mathrm{kg}$.

Finally, it remains to take into account the energy required to capture the $\mathrm{CO}_{2}$ required for methanol production to obtain the net energy efficiency of the proposed methanol production, transportation and distribution process. To produce 70,000 tonnes of methanol per annum, 94,500 tonnes of $\mathrm{CO}_{2}$ are required. The corresponding energy requirement is in the range 66 to $246 \mathrm{GWh}$ per annum depending on the technology used for carbon capture and whether waste heat from the methanol combustion can be used. Assuming that this energy is provided through methanol combustion, 12,000 to 44,700 tonnes are required. This increases the energy requirement of methanol production to 14.9 to 37.6 $\mathrm{kWh} / \mathrm{kg}$.

Therefore, the net energy efficiency of methanol production, transportation and distribution in FARWIND energy systems is 15 to $37 \%$, which includes the energy cost of $\mathrm{CO}_{2}$ production. This efficiency is significantly smaller than that of FARWIND energy systems producing hydrogen as the energy vector (approx. 50\% [16]). Excluding the energy cost of $\mathrm{CO}_{2}$, the efficiency increases to $45 \%$, rather close to that of hydrogen.

\section{ESTIMATE OF THE METHANOL COST}

A power-to-methanol plant for direct methanol synthesis comprises a water electrolyzer, two reactors, a methanol distillation unit, a pressure swing absorption unit, and compressors [22]. The electrolyzer represents $70 \%$ of the capital cost of the plant. According to [41], the cost of alkaline-based electrolyzer system cost is expected to decrease to $900 € / \mathrm{kW}$ in close future (2025), and the operation and maintenance (O\&M) cost is $4 \%$. Therefore, we assume a capital costs of $1,300 € / \mathrm{kW}$ for the power-to-methanol (1.3 M€ for the 1MW plant of a FARWINDER), and $4 \%$ for the O\&M cost.

According to [42], the capital cost of a 4,600 tonnes cargo ship is 11 MUS\$, thus approximately $10 \mathrm{M} €$. Following [43], it is assumed that the O\&M cost for the tanker is $7 \%$ of the capital cost.

According to [44], the cost of delivery by truck is 0.5 $€$ per $\mathrm{km}$ plus $170 €$ per day plus $23 €$ per drive hour. Therefore, the additional cost for delivering methanol at a distance of $600 \mathrm{~km}$ from the terminal is in the order of $0.04 € / \mathrm{kg}$.

TABLE II. COST ESTIMATE FOR THE FARWIND ENERGY SYSTEM

\begin{tabular}{|c|c|c|c|}
\hline & Unit cost & Number & $\begin{array}{c}\text { FARWIND } \\
\text { energy sytem }\end{array}$ \\
\hline \multicolumn{4}{|l|}{ Capital cost } \\
\hline $\begin{array}{l}\text { Power-to-methanol } \\
\text { plant }\end{array}$ & $1,300 \mathrm{k} €$ & 112 & 145.6 M€ \\
\hline Tanker & $10,000 \mathrm{k} €$ & 5 & $50 \mathrm{M} €$ \\
\hline \multicolumn{3}{|c|}{ Total capital cost } & $195.6 \mathrm{M€}$ \\
\hline \multicolumn{4}{|l|}{$O \& M$ cost } \\
\hline $\begin{array}{l}\text { Power-to-metanol } \\
\text { plant/electricity }\end{array}$ & $80 € / \mathrm{MWh}$ & $784 \mathrm{GWh} / \mathrm{a}$ & $62.7 \mathrm{M} €$ \\
\hline $\begin{array}{l}\text { Power-to-methanol } \\
\text { plant } / \mathrm{CO}_{2}\end{array}$ & $20-200 € / \mathrm{t}$ & $94,500 \mathrm{t} / \mathrm{a}$ & $1.89-18.9 \mathrm{M} €$ \\
\hline $\begin{array}{l}\text { Power-to-metanol } \\
\text { plant/maintenance }\end{array}$ & \multicolumn{2}{|c|}{$4 \%$ of capital cost } & $5.8 \mathrm{M} €$ \\
\hline Tanker & \multicolumn{2}{|c|}{$7 \%$ of capital cost } & $3.5 \mathrm{M} €$ \\
\hline \multicolumn{3}{|c|}{ Total O\&M cost } & $73.9-90.9 \mathrm{M} €$ \\
\hline Distribution cost & $0.04 € / \mathrm{kg}$ & $66,170 \mathrm{t} / \mathrm{a}$ & $2.6 \mathrm{M} €$ \\
\hline
\end{tabular}

Finally, let us consider the $\mathrm{CO}_{2}$ production cost. It depends on the technology. In [35], a range of 80 to 204 $€ /$ tonne $_{\mathrm{CO} 2}$ is reported for a wet absorption DAC technology. According to [45], carbon capture from coalfired power plant is at least $53 € /$ tonne with current technology. New technologies are in development which may reduce cost to $20 € /$ tonne. The cost of carbon capture for several industrial applications is given in [46]. The lower cost ( $\sim 18 € /$ tonne) is obtained for natural gas and biomass to ethanol processes. The higher cost is obtained for cement production ( $\sim 90 € /$ tonne). The cost for power production from coal or natural gas is in the middle ( $\sim 35-50 € /$ tonne). Therefore, we will retain 20 $€ /$ tonne for the low end of the range of $\mathrm{CO} 2$ production cost, and $200 € /$ tonne for the high end. 
Tab. 2 summarizes the cost data for the proposed FARWIND energy system. We recall that it comprises 112 FARWINDERs and 5 tankers (see previous section). For the FARWINDERs, only the cost of the power-tomethanol plant is considered in the capital cost because other cost sources are already taken into account in the cost of electricity available on-board. Using the cost data and assuming that the lifetime of the system is 20 years and that the capital recovery factor is $9 \%$ (interest rate of $7 \%$ ), the methanol cost can be estimated [43]. It leads to a cost in range of 1.42 to $1.68 € / \mathrm{kg}$ (259 to $305 € / \mathrm{MWh}_{\text {th }}$ ) depending on the cost of $\mathrm{CO}_{2}$.

The cost of FARWIND-produced methanol would then be 4 to 5 times greater than the current methanol market price $\left(\sim 60 € / \mathrm{MWh}_{\text {th }}\right)$, which is obviously a critical issue for the commercial development of the FARWIND technology. However, the current methanol market price does not take into account a price on GHG emissions. At least $0.675 \mathrm{~kg}$ of $\mathrm{CO}_{2}$ is produced per $\mathrm{kg}$ of methanol produced using conventional processes (which are based on coal or natural gas) [47]. In 2018, the carbon tax was $44.6 € /$ tonne in France (respectively approximately 110 $€ /$ tonne in Sweden), which would increase the methanol price by $5.5 € / \mathrm{MWh}_{\text {th }}$ if $\mathrm{CO}_{2}$ emissions are taken into account (respectively $13.5 € / \mathrm{MWh}_{\text {th }}$ ). Thus, even with a fairly high carbon tax, the cost of FARWIND-produced methanol would not be competitive.

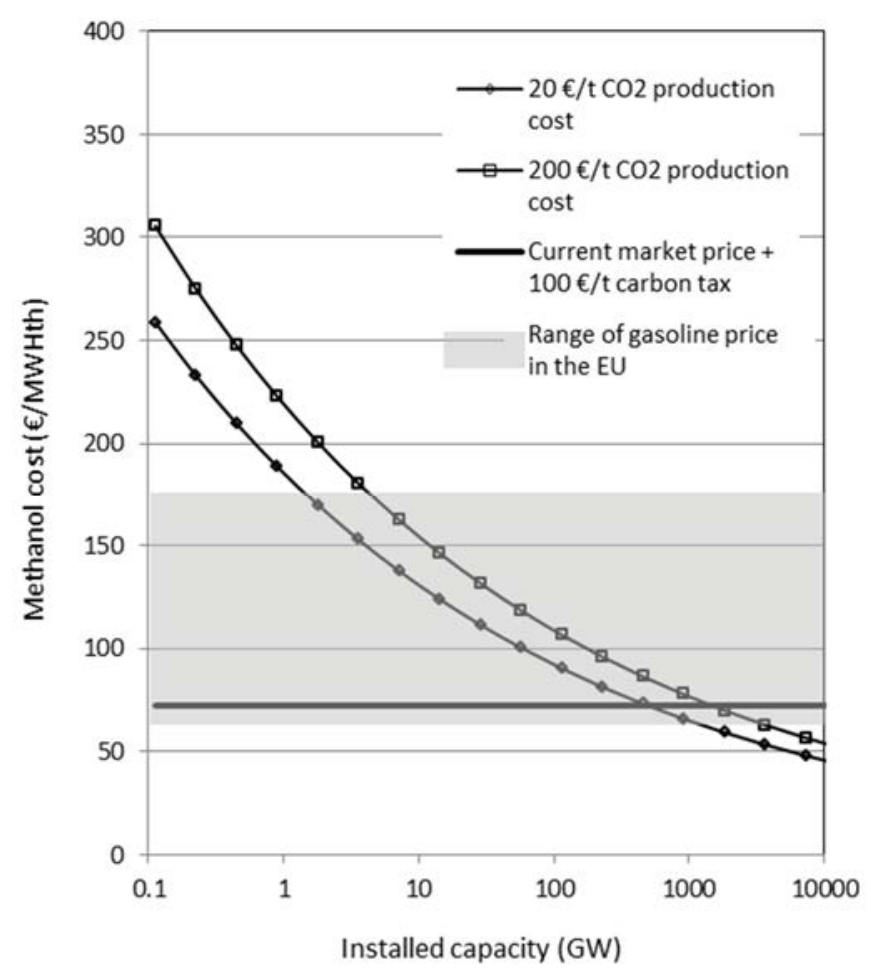

Fig. 4: Methanol cost as function of installed capacity assuming a learning rate of $10 \%$
As described in Tab. 2, the transportation (tanker) and distribution cost are low in comparison to the production cost (power-to-methanol plant, electricity cost, $\mathrm{CO}_{2}$ production cost). They are estimated to be in the order of $0.12 € / \mathrm{kg}$, i.e. less than $10 \%$ of the total methanol cost. It is significantly smaller than the transportation and distribution cost for a hydrogen solution (in the order of $50 \%$ according to [16]).

However, it may be argued that this cost is for a firstof-its-kind FARWIND energy system. One can expect that the cost would reduce with the development of the technology. Fig. 4 shows the methanol cost as function of the installed capacity assuming a learning rate of $10 \%$ (as was observed for wind turbines [48]). One can see that, for a $\mathrm{CO} 2$ production cost of $20 € /$ tonne and a methanol price of $72 € / \mathrm{MWh}_{\text {th }}$ (current market price plus $100 € /$ tonne carbon taxe), $\quad$ FARWIND-produced methanol could become cost competitive once the installed capacity would be over $500 \mathrm{GW}$. For the sake of comparison, the global installed capacity of installed wind turbines, which are now cost competitive for power generation, was $539 \mathrm{GW}$ in 2017 (it is expected to reach $840 \mathrm{GW}$ in 2022) [49]. In contrast, for a $200 € /$ tonne $\mathrm{CO}_{2}$ production cost assumption, the required installed capacity would be in the order of 1,500 GW. Thus, it appears that the $\mathrm{CO}_{2}$ production cost is an important driver for the long term competitiveness of FARWINDproduced methanol.

Finally, let us consider the perspective of the fuel transportation market, for which methanol could displace gasoline. Indeed, flexible fuel vehicles which can run with a $85 \%$ methanol $15 \%$ gasoline mix (M85 fuel) have been developed and commercialized (e.g. the 1996 Ford Taurus); and M100 (100\% methanol) vehicles are in development. At present, the gasoline price in the EU is in the range 0.63 (Belarus) to $1.7 € / \mathrm{L}$ (Netherlands). It corresponds to 64 to $173 € / \mathrm{MWh}_{\text {th }}$ as the standard density of gasoline traded in the EU is $0.755 \mathrm{~kg} / 1$ and its energy content is approximately $13 \mathrm{kWh}_{\mathrm{th}} / \mathrm{kg}$. The price differences can be explained by different policies on fuel taxes depending on the countries.

Compared to the energy cost of gasoline, it appears that the competitivity gap of energy from FARWINDproduced methanol (1.5 to 4.7 ) is significantly less than when compared to market price of methanol produced from fossil fuels. In Fig. 4, it can be seen that competitiveness could be achieved once the installed capacity would be over $2 \mathrm{GW}$ in the best case scenario $\left(\mathrm{CO}_{2}\right.$ production cost of $20 € /$ tonne and energy price of $173 € / \mathrm{MWh}_{\text {th }}$ ), which is two orders of magnitude less than when considering the methanol market. Moreover, despite the fact that cost competitiveness would still be difficult to achieve for the worst case scenario $\left(\mathrm{CO}_{2}\right.$ 
production cost of $200 € /$ tonne), it could be achieved for an installed capacity in the order of $30 \mathrm{GW}$ for an average scenario $(\mathrm{CO} 2$ production cost of $110 € /$ tonne and energy price of $119 € / \mathrm{MWh}_{\mathrm{th}} / 1.16 € / \mathrm{L}$ of gasolineequivalent). This result is very promising.

\section{CONCLUSIONS}

In this paper, options for the energy vector produced by FARWIND energy systems were compared. Methanol was selected because of the good energy efficiency of the production process, its high market value and the fact that it is in liquid phase for standard conditions of temperature and pressure.

Then, the energy efficiency of energy storage, transportation and distribution was evaluated for methanol-producing FARWIND energy sytems. Excluding the $\mathrm{CO}_{2}$ production energy cost, the efficiency is found to be $45 \%$ When the $\mathrm{CO}_{2}$ production cost is taken into account, the efficiency decreases to 15 to $37 \%$ depending on the technology for carbon capture. This is significantly smaller than when the energy vector is hydrogen (in the order of 50\% according to [16]).

With respect to cost, it is found that FARWINDproduced methanol may be cost competitive with gasoline on the transportation fuel market. A key driver is the $\mathrm{CO}_{2}$ production cost. Moreover, the transportation and distribution cost were found to be less than $10 \%$ of the total methanol cost, which is significantly smaller than for the hydrogen solution. Those results indicate that methanol may be the best energy vector for FARWIND energy systems, and that FARWIND energy systems have great potential for future sustainable fuel supply.

\section{REFERENCES}

[1] P. Capros, A. De Vita, N. Tasios, P. Siskos, M. Kannavou, A. Petropoulos, et al., EU Reference Scenario 2016 - Energy, transport and GHG emissions: trends to 2050. Brussels, Belgium: The European Commission, 2016.

[2] M. Gotz, J. Lefebvre, F. Mors, A. McDaniel Koch, F. Graf, S. Bajohr, et al., "Renewable power-to-gas: a technological and economic review", Renewable Energy, vol. 85, pp.1371-1390, 2016

[3] https://www.jupiter1000.eu/

[4] https://soletair.fi/

[5] D.S. Marlin, E. Sarron, I. Sigurbjornsson, "Process advantages of direct $\mathrm{CO} 2$ to methanol synthesis". Frontiers in chemistry, vol. 6,2018

[6] M. Fasihi, D. Bogdanov, C. Breyer, "Techno-economic assessment of power-to-liquid (PtL) fuels production and global trading based on hybrid PV-wind power plants", Energy Procedia, vol. 99, pp. 243-268, 2016

[7] M.F. Platzer, N. Sarigul-Klijn, "Energy ships and plug-in electric vehicles: are they the key for a rapid transition to an emission-free economy?", in Proc. of the ASME 2015 IMECE conference, Houston, Texas, 2015

[8] J-C. Gilloteaux, A. Babarit, "Preliminary design of a wind driven vessel dedicated to hydrogen production", in Proc. of the ASME 2017 36th International conference on ocean, offshore and artic engineering (OMAE), Trondheim, Norway, 2017
[9] P.F. Pelz, M. Holl, M. Platzer, "Analytical method towards an optimal energetic and economical wind-energy converter", Energ, vol. 94, pp. 344-351, 2016

[10] H. Chen, T. Ngoc-Cong, W. Yang, C. Tan, Y. Li, Y. Ding, «Progress in electrical energy storage system: a critical review", Progress in Natural Science, vol. 19, pp. 291-312, 2009.

[11] https://nelhydrogen.com/product/c-range/

[12] R.E. Salomon, Process of converting wind energy to elemental hydrogen and apparatus therefor. U.S. Patent 4335093A, 1982

[13] M.F. Platzer, N. Sarigul-Klijn, "A novel approach to extract power from free-flowing water and high-altitude jet streams", in Proc. Of the ASME 2009 3rd International conference on energy sustainability Vol. 1, San Francisco, California, USA, 2009

[14] J. Kim, C. Park, "Wind power generation with a parawind on ships, a proposal", Energy, vol. 35, pp. 1425-1432, 2010

[15] K. Ouchi, J. Henzie, "Hydrogen generation sailing ship: conceptual design and feasibility study", in Proc. Of IEEE OCEANS 2017 conference, 2017

[16] A. Babarit, J-C Gilloteaux, G. Clodic, M. Duchet, A. Simoneau, M.F. Platzer, "Techno-economic feasibility study of fleets of far offshore hydrogen-producing wind energy converters", International Journal of Hydrogen Energy, vol. 43(15), pp. 7266-7289, 2018

[17] https://en.wikipedia.org/wiki/HMAS Jervis Bay (AKR 45)

[18] www.norsepower.com

[19] A. Babarit, G. Clodic, E. Body, A. Simoneau, J-C. Gilloteaux, "Sustatinable methanol production from the far-offshore wind energy resource". Unpublished

[20] P. Schmidt, W. Weindorf, A. Roth, V. Batteiger, F. Riegel (2016) Power-to-Liquids - Potentials and perspectives for the future supply of renewable aviation fuel. Background paper, Unweltbundesamt, $36 \mathrm{pp}$.

[21] R. Otten, "The first industrial PtG plant -Audi e-gas as driver for the energy turnaround". Presentation made at CEDEC gas day 2014 , may $27^{\text {th }} 2014$

[22] B. Anicic, P. Trop, D. Goricanec, "Comparison of two methods of methanol production from carbon dioxide". Energy, vol. 77, pp 279-289, 2014

[23] M.F. Platzer, N. Sarigul-Klijn, "Carbon-neutral jet fuel production from seawater", International journal of sustainable aviation, vol. 2(2), 2016

[24] B. Stefansson, "Power and CO2 emissions to methanol". Presentation, 2015 European methanol policy forum, Brussel, 2015

[25] C.F.R. Machado, J.L. de Medeiros, O.F.Q. Araujo, "A comparative analysis of methanol production routes: synthesis gas versus $\mathrm{CO}_{2}$ hydrogenation". In Proc. Of the 2014 International conference on indsutrial engineering and pperations management, Bali, Indonesia, 2014

[26] http://www.climeworks.com/

[27] C. Philibert, Producing ammonia and fertilizers: new opportunities from renewables. International energy agency, renewable energy division, May 16, 2017

[28] NFUEL Slidepack information. Proton Ventures, Schiedam, 2018

[29] E.R. Morgan, Techno-economic feasibility of ammonia plants powered by offshore wind. Amherst, MA: University of Massachussets, Dissertations, 697, 2013

[30] R. Abd-Jamil, A. Chaigneau, J-C. Gilloteaux, A. Babarit, "Comparison of the capacity factor of stationary wind turbines and weather-routed energy ships in the far-offshore", in Proc. Of the 15th Deep Sea Offshore Wind Energy Conference (EERA DeepWind'2018), Trondheim, Norway, 2019

[31] Chart, Technical manual: carbon dioxide storage tank. Manual \#11650869 Rev 1

[32] https://www.gitank.com/methanol-storage-tanks

[33] MAN, Propulsion trends in bulk carriers. 
[34] M.Z. Jacobson, M.A. Delucchi, Z.A.F. Bauer, S.C. Goodman, W.E. Chapman, M.A. Cameron et al., " $100 \%$ clean and renewable wind, water, and sunlight all-sector energy roadmaps for 139 countries of the world". Joule, vol. 1(1), pp. 108-121, 2017

[35] D.W. Keith, G. Holmes, D. St Angelo, K. Heidel, "A process for capturing $\mathrm{CO} 2$ from the atmosphere", Joule, vol. 2, pp. 15731594, 2018

[36] D.Y.C. Leung, G. Caramanna, M.M. Maroto-Baler, “An overview of current status of carbon dioxide capture and storage technologies". Renewable and Sustainable Energy Reviews, vol. 39, pp. 426-443, 2014

[37] H.D. Willauer, D.R. Hardy, K.R. Schultz, F.W. Williams, "The feasibility and current estimated capital costs of producting jet fuel at sea using carbon dioxide and hydrogen". Journal of Renewable and sustainable energy, vol. 4, 2012

[38] H.D. Willauer, F. DiMascio, D.R. Hardy, "Extraction of carbon dioxide and hydrogen from seawater by an electrolytic cation exchange module (E-CEM) part V: E-CEM effluent discharge composition as a function of electrode water composition". Washington D.C.:Naval research laboratory, 2017

[39] L.E. Oi, N. Eldrup, U. Adhikari, M.H. Bentsen, L. Badalge, S. Yang, "Simulation and cost comparison of $\mathrm{CO} 2$ liquefaction", Energy procedia, vol. 86, pp. 500-510, 2016

[40] http://ycdtauto.com/113-.html

[41] C. Chardonnet, L. De Vos, F. Genoese, G. Roig, V. Giordano, S. Rapoport, et al., Study on early business cases for $\mathrm{H} 2$ in energy storage and more broadly power to $\mathrm{H} 2$ applications - a study prepared for the FCH-JU Tractebel and Inicio. Brussels, Belgium: Tractebel engineering, 2017

[42] H. Lindstad, B.E Asjornslett, A.H. Stromman, "The importance of economies of scale for reductions ingreenhouse gas emissions from shipping". Energy policy, vol. 46, pp. 386-398, 2012

[43] M. Holl, L. Rausch, P.F. Pelz, "New methods for new systems How to find the techno-economically optimal hydrogen conversion system". International Journal of Hydrogen Energy, vol. 42, pp. 22641-22654, 2017

[44] http://www.cnr.fr/Indices-Statistiques/Regional-EA/Referentielprix-de-revient

[45] T. Lockwood, "A compative review of next-generation carbon capture technologies for coal-fired power plant". Energy procedia, vol. 114 , pp. 2658-2670, 2017

[46] L. Irlam, Global costs of carbon capture and storage - 2017 update. Global CCS institute, June 2017

[47] M. Martin, I.E. Grossmann, "Towards zero CO2 emissions in the production of methanol from switchgrass. $\mathrm{CO}_{2}$ to methanol". Computers and chemical engineering, vol. 105, pp. 308-316, 2017

[48] A. Lindman, P. Soderholm, "Wind power learning rates: a conceptual review and meta-analysis". Energy economics, vol. 34, pp. 754-761, 2012

[49] Global wind energy council, Global wind report - annual market update 2017,2017 